\title{
The relative importance of patch habitat quality and landscape attributes on a declining steppe-bird metapopulation
}

\author{
Matthias Vögeli ${ }^{\mathrm{a}, *}$, David Serrano ${ }^{\mathrm{a}}$, Fernando Pacios ${ }^{\mathrm{a}, \mathrm{b}}$, José L. Tella ${ }^{\text {a }}$ \\ ${ }^{a}$ Department of Conservation Biology, Estación Biológica de Doñana (CSIC), C/Américo Vespucio s/n, 41092 Sevilla, Spain \\ ${ }^{\mathrm{b}} \mathrm{C} /$ Alhóndiga $431^{\circ} \mathrm{B}, 41003$ Sevilla, Spain
}

Keywords:

Chersophilus duponti

Connectivity

Dupont's lark

Habitat quality

Landscape matrix

Occurrence

Patch size

\begin{abstract}
a b s t r a c t
Metapopulation theory is one of the most popular approaches to identify the factors affecting the spatial and temporal dynamics of populations in fragmented habitat networks. Habitat quality, patch area and isolation are mainly focused on when analyzing distribution patterns in fragmented landscapes. The effects of landscape heterogeneity in the non-occupied matrix, however, have been largely neglected. Here, we determined the relative importance of patch quality and landscape attributes on the occurrence, density and extinction of the Dupont's lark (Chersophilus duponti), an endangered steppe passerine whose habitat has been extremely reduced to highly isolated and fragmented patches embedded in a mainly unsuitable landscape matrix. Habitat patch quality, measured in terms of vegetation structure, grazing pressure, arthropod availability, predator abundance, and inter-specific competition, did not affect occurrence, density or extinction. At the landscape scale, however, the species' occurrence was principally determined by the interactions among patch size, geographic isolation and landscape matrix. Isolation had the main independent contribution to explaining the probability of occurrence, followed by landscape matrix composition and patch size. The species' density was negatively correlated to patch size, suggesting crowding effects in small fragments, while extinction events were exclusively related to isolation. Our findings suggest that landscape rather than local population characteristics are crucial in determining the patterns of distribution and abundance of non-equilibrium populations in highly fragmented habitat networks. Consequently, conservation measures for these species should simultaneously involve patch size, isolation and landscape matrix and apply to the entire metapopulation rather than to particular patches.
\end{abstract}

\section{Introduction}

Anthropogenic habitat destruction and fragmentation are nowadays recognized as major environmental threats to the persistence of species. Small and declining populations have consequently become paradigms for conservation biology (Caughley, 1994). While the habitat becomes increasingly fragmented, regional processes gain importance in the overall persistence of populations. In this sense, metapopulation theory is one of the most popular approaches to identify the factors affecting the spatial and temporal dynamics of populations of species living in fragmented habitat networks (Hanski and Gilpin, 1997). Two crucial metapopulation processes are driven by local and regional dynamics according to their patch size and isolation (or inversely, connectivity): Stochastic extinctions increase with decreasing patch size, and the (re)colonization probability of empty patches decreases with increasing isolation (Hanski and Gilpin, 1997). Hence, small

\footnotetext{
* Corresponding author. Tel.: +34 954466700; fax: +34 954621125

E-mail address: matthias@ebd.csic.es (M. Vögeli).
}

and isolated patches are predicted to have a smaller probability of occupancy than large and well-connected ones. Indeed, the combination of patch size and connectivity has often adequately described patterns of animal occurrence for many taxa in fragmented landscapes (Prugh et al., 2008). Nevertheless, the effects of habitat quality and landscape matrix quality have received much less attention in these studies.

Despite the need of integration of habitat characteristics and metapopulation effects to understand species' declines or extinctions, habitat patch quality has not been explicitly integrated into metapopulation modeling until a few years ago (Thomas et al., 2001). Since then, habitat quality has been increasingly included in metapopulation studies and proven to strongly determine species occurrence, colonization or extinction patterns (e.g. Jaquiéry et al., 2008). Nevertheless, assessing habitat quality is not a trivial issue and its relative importance to that of area and isolation remains controversial and largely underinvestigated (e.g. Rabasa et al., 2008).

Classical metapopulation theory divided landscape into habitat and matrix (i.e. the nonhabitat surrounding the habitat patches of 
interest) and assumed the latter to be uniform in its resistance to the movements of individuals among patches. However, recent research has shown that matrix heterogeneity strongly influence interpatch movements (Ricketts, 2001), and might consequently equal or even outnumber the effects of patch size and isolation on species' distributions.

Here, we used the Dupont's lark (Chersophilus duponti) as a model species to determine the relative importance of withinpatch habitat quality, and landscape attributes at the metapopulation level (grouped into patch size, connectivity and landscape matrix quality) on occurrence, density and extinction in a highly fragmented landscape. This threatened species is restricted to natural steppes in Europe and North Africa, and has continuously negative population trends due to drastic habitat loss and fragmentation (Cramp, 1988; Tella et al., 2005; BirdLife, 2008). We analyzed the habitat characteristics inside the surveyed steppe patches by (a) vegetation structure, botanical composition and grazing pressure, (b) food availability, (c) densities and richness of potentially competing bird species, and (d) predator abundance. At the metapopulation level, we employed three different predictor groups: (a) habitat patch size, (b) patch connectivity, and (c) landscape matrix. In a second step, we used a modified form of the variation partitioning method (Borcard et al., 1992) to decompose the total deviance of occupancy models into the components according with the employed predictor groups. The independent effects of explanatory variables were subsequently separated from those accounting for spatial autocorrelation. Finally, we applied a hierarchical partitioning analysis to determine the independent contribution made by the most determinant single factors for each predictor group (Mac Nally, 2000). The different steps of this approach allowed us to disentangle and identify the most important effects of multiple and interacting environmental factors (Heikkinen et al., 2005).

\section{Materials and methods}

\subsection{Study model species}

The Dupont's lark inhabits exclusively flat steppe areas with natural vegetation in semiarid regions of Spain and Northern Africa (Cramp, 1988). Considered as one of the less abundant European passerine species, it is categorized as Endangered in Spain due to past and ongoing habitat loss, mainly because of agricultural expansion (Garza et al., 2004). In the Ebro Valley, the second most stronghold of Dupont's lark in Spain, ca. $40 \%$ of its populations have disappeared in recent decades (Tella et al., 2005), and habitat destruction and fragmentation has been suggested to disrupt the population dynamics of the remaining Dupont's lark populations (Laiolo et al., 2008). Due to fast anthropogenic changes involving predominantly farming intensification since the 1950s, most natural vegetation in this region has been reduced to highly isolated and fragmented patches embedded in a matrix dominated by agriculture (Laiolo and Tella, 2006).

\subsection{Study area}

The surveyed pseudosteppe area in the Ebro Valley (NE Spain) covered approximately $14,000 \mathrm{~km}^{2}$ mainly characterized by widespread non-irrigated cereal cultivations forming mosaics with other habitats including natural vegetation, dry legumes and fallows, combined with sheep grazing. The analyzed patches of natural steppe vegetation consisted of one or various fragments of adequate habitat for the Dupont's lark. Fragments separated by less than $1 \mathrm{~km}$ from the next neighbor fragment were assigned to the same patch given that more than $95 \%(n=427)$ of all within-terri- tory lark movements detected with acoustic and physical marking ( $n=440$ ) occurred within these distance (Vögeli et al., 2008; Vögeli, Laiolo, Serrano, Tella, unpubl. data). These movements included larks crossing unsuitable habitat (e.g. cereal cultivations) by flight or run (Vögeli, Laiolo, Serrano, Tella, pers. obs.).

\subsection{Dupont's lark census}

The Dupont's lark is complicated to observe due to its cryptic color, elusive behavior and reluctance to fly, and most contacts are therefore auditory. The species' unusually strong song and territorial call can be heard at a distance until $1500 \mathrm{~m}$ (Laiolo et al., 2007). Consequently, the distances to vocalizing birds are often underestimated. Correct distance estimation, however, is crucial for line transect counts, and the erroneous assignations of birds to the inner belt of a transect line can cause large overestimations of Dupont's lark densities (Tella et al., 2005). Furthermore, singing males often stop vocalizing when they detect an approaching human (sometimes at 50-80 m), run away without taking flight and begin to sing again some time later at varying distances, which can lead to repeatedly count the same individual (Tella et al., 2005). Hence, the use of line transects is not valid for censusing Dupont's lark. We applied therefore a census technique based on territory mapping (Tella et al., 2005). Between 2004 and 2007, the different patches were repeatedly visited in each spring (March-June). All Dupont's lark locations ( $\mathrm{n}=2035)$ were recorded with a handheld GPS and mapped to determine the distinct territories. Observations of individually color-banded birds for a markcapture-recapture study that was simultaneously carried out (Vögeli et al., 2008) facilitated this task.

\subsection{Occurrence, density, and transect sampling of habitat characteristics}

During the breeding seasons (April-May) of 2005 and 2006, we established 86 linear transects in 30 different patches of natural steppe vegetation potentially adequate for the Dupont's lark. Transect lines had a maximum length of $500 \mathrm{~m}$ and were spaced more than $200 \mathrm{~m}$ apart if several transects were carried out in the same steppe patch. The number of transects per patch was approximately proportional to its size (Tellería et al., 2008). Within the sampled patches (see Section 2.5.1 below for a characterization of patch boundaries), which could consist of various fragments of adequate habitat for Dupont's lark, the length of transects was adjusted to the fragment size if the maximum linear length could not be reached. We established maximal 100 m-wide belts on each side of the transect line adjusting the borders to the natural vegetation potentially adequate for Dupont's lark just as for the whole steppe patch (see Section 2.5.1 below) and calculated the size of each transect area. This belt was chosen because Dupont's lark density is relatively low (one territory per 10 ha; Garza et al., 2005) and narrower belts would lead to poorly accurate density estimates, even of zero in those patches where the species holds very low densities.

Based on the territory mapping census in 2007, we assessed a posteriori the species' occurrence inside each steppe patch and transect, respectively. The species was present in 18 patches, characterized by 52 transects, whereas it lacked in the other 12 patches where 34 transects were carried out (Appendix A). Likewise, we determined the maximal number of territories inside each transect. To get a density value for each transect, we divided the number of territories obtained by territory mapping by the respective area of natural vegetation potentially adequate for the species.

Along the transect lines, we established five equidistantly separated sampling points where the vegetation structure, botanical composition, soil type and arthropod availability were recorded. 
Grazing pressure and densities of other passerines were estimated from counts performed along the same transect line (see below). All these recorded variables are resumed in Appendix B.

\subsubsection{Vegetation and grazing pressure}

Based on direct recording in circular plots of 25 m-radius around each sampling point, we estimated visually the vegetation structure with means of ground coverage percentages (e.g. Carrete et al., 2009). We recorded the height of the four closest specimens of both shrubs and herbs at each sampling point, and computed the mean value of the corresponding plant group. The final value for a continuous variable characterizing vegetation structure in a single transect was obtained as the average value for all sampling points. We registered furthermore the predominating plant species to determine the vegetation communities (Appendix C). Finally, the number of sheep feces along each transect was counted to evaluate the grazing pressure, which may affect densities of steppe passerines (Carrete et al., 2009).

\subsubsection{Arthropod availability}

Dupont's lark is predominantly insectivorous, feeding on a large range of ground-dwelling arthropods (Cramp, 1988), and should therefore benefit from a high diversity and abundance of arthropods. Between May and June in 2005 and 2006, we installed five pitfall traps (opening diameter $6 \mathrm{~cm}$, height $8 \mathrm{~cm}$, filled with $70 \%$ ethyl alcohol) in each transect to characterize their arthropod abundance and species diversity. Trap locations were determined randomly but separated by at least $25 \mathrm{~m}$ from each other to account for the potential influence of microclimate and vegetation structure. After 3 days, we emptied the traps and filtered and washed the contents, which were stored in $70 \%$ ethyl alcohol. 596 traps remained for examination once the traps with evident signs of disturbance or manipulation (mostly by rabbits or sheep) were discarded. All specimens were identified to species level when possible or otherwise to morphospecies and labeled as recognizable taxonomic units (RTUs) (Oliver and Beattie, 1993). To minimize observer bias, all identification and classification work was carried out by the same investigator (MV). For each transect we counted the number of RTUs trapped and calculated a biomass index (weighing the RTU abundance against its respective mean body length) as the average value obtained for all sampling points. Based on the obtained numbers of RTUs, we computed furthermore a species diversity index of each transect (Shannon and Weaver, 1949).

\subsubsection{Bird densities and species richness}

Based on line-transects recording all birds detected by sight or sound inside and outside $50 \mathrm{~m}$-wide belts on either side of our established transects (Carrete et al., 2009), we calculated the total density of the steppe passerine species that potentially compete in the breeding season with the Dupont's lark for habitat and food (Cramp, 1988; Appendix D). Censuses were performed from $1 \mathrm{~h}$ after dawn until noon, avoiding rainy and windy days (Carrete et al., 2009). For each patch, we calculated its correspondent species diversity index (Shannon and Weaver, 1949).

\subsubsection{Predator abundance}

During field work from the beginning of spring 2004 until the end of spring 2007, we recorded all observations of (a) nest predators and (b) passerine hunting aerial predators (Appendix E). We calculated a relative abundance index for each predator group by dividing the observations (nest predators: $n=1098$, aerial predators: $n=659$ ) by the time spent in the respective steppe patch, which totalized $3506 \mathrm{~h}$.
2.5. Occurrence, density, and GIS analyses of landscape attributes at the metapopulation level

We analyzed 65 patches at the metapopulation level (Fig. 1), including all known patches in our study area where the species' presence has been detected $(n=40)$. Although we carried out intensive search throughout our study area, we cannot exclude the possible existence of a few additional occupied patches due to the species' elusive behavior and low vocal activity in patches with a small population size (Laiolo and Tella, 2008). Nevertheless, we are confident that undetected populations constitute a minimum percentage of the whole metapopulation with a negligible effect on the outcomes of this study. In 12 of 25 patches where the species was absent, it has recently gone extinct, whereas its presence in the other 13 has never been detected (Appendix A). To calculate Dupont's lark density in each patch, we divided the mean number of occupied territories by the area of natural vegetation potentially adequate for the species (see below). The variables characterizing the landscape attributes at the metapopulation level are described below and summarized in Appendix F.

\subsubsection{Patch size}

To identify the area of natural vegetation potentially adequate for the Dupont's lark, we intersected all locations of the species obtained during our study $(n=2035)$ with a highly detailed land-use map (SIGPAC, 2008). Then, we adjusted manually the area of these selected plots with the help of high-resolution (1:5000) aerial orthophotographs made in 2006. Most of the discarded surface consisted of steppe habitat with an exceeding inclination (slopes steeper than 5\%; Seoane et al., 2006), which had previously been identified and recorded during fieldwork. At the metapopulation level, the identification of adequate habitat for Dupont's lark was strongly alleviated by the fact that the vast majority of surveyed patches are island-like remnants in a landscape dominated by agriculture, and the boundaries between natural steppe and other land uses are easily recognizable. We repeated then the procedure selecting patches without Dupont's lark presence, using all previous information about the species' presence where possible (Aragüés, 1992). Eventually, all the resulting steppe patches were digitalized to calculate their patch size and geographic centre.

\subsubsection{Connectivity}

We calculated four connectivity indices after Hanski et al. (1994) to characterize the connectivity among the patches at the metapopulation level. The first two indices were the distances from patch $i$ to the nearest occupied patch $\left(\mathrm{C}_{1}\right)$ and to the average coordinate of all patches $\left(\mathrm{C}_{2}\right)$. The third connectivity index was defined as follows: $C_{3}=R \exp \left(-d_{i j}\right) N_{j}$, where $d_{i j}$ is the distance between patches $i$ and $j, N_{j}$ is the population size of patch $j$, including only occupied patches. Eventually, we calculated a connectivity index weighting the respective distances to four distinct patches: $C_{4}=R$ exp $\left(-d_{i k}\right)$, where $d_{i k}$ is the distance between patches $i$ and patches $k_{1}-k_{4}$ (see Appendix A). These four patches were the only subpopulations with positive values in terms of population viability, characterized by the mean annual geometric rate of population change $(k>1)$ (Laiolo et al., 2008, Fig. 1). With exception of $\mathrm{C}_{1}$, where the shortest distance between the edges of the corresponding patches was measured, we used the geographic patch centers to calculate the connectivity indices.

\subsubsection{Landscape matrix}

Around each patch we established a buffer ring with $20 \mathrm{~km}-\mathrm{ra}-$ dius from the patch edge, according to the maximum dispersal distance of Dupont's larks detected in our study area (Laiolo, unpubl. data). Then we clipped these buffers with CORINE land cover digital maps derived from orthodigital aerial photographs of the Ibe- 


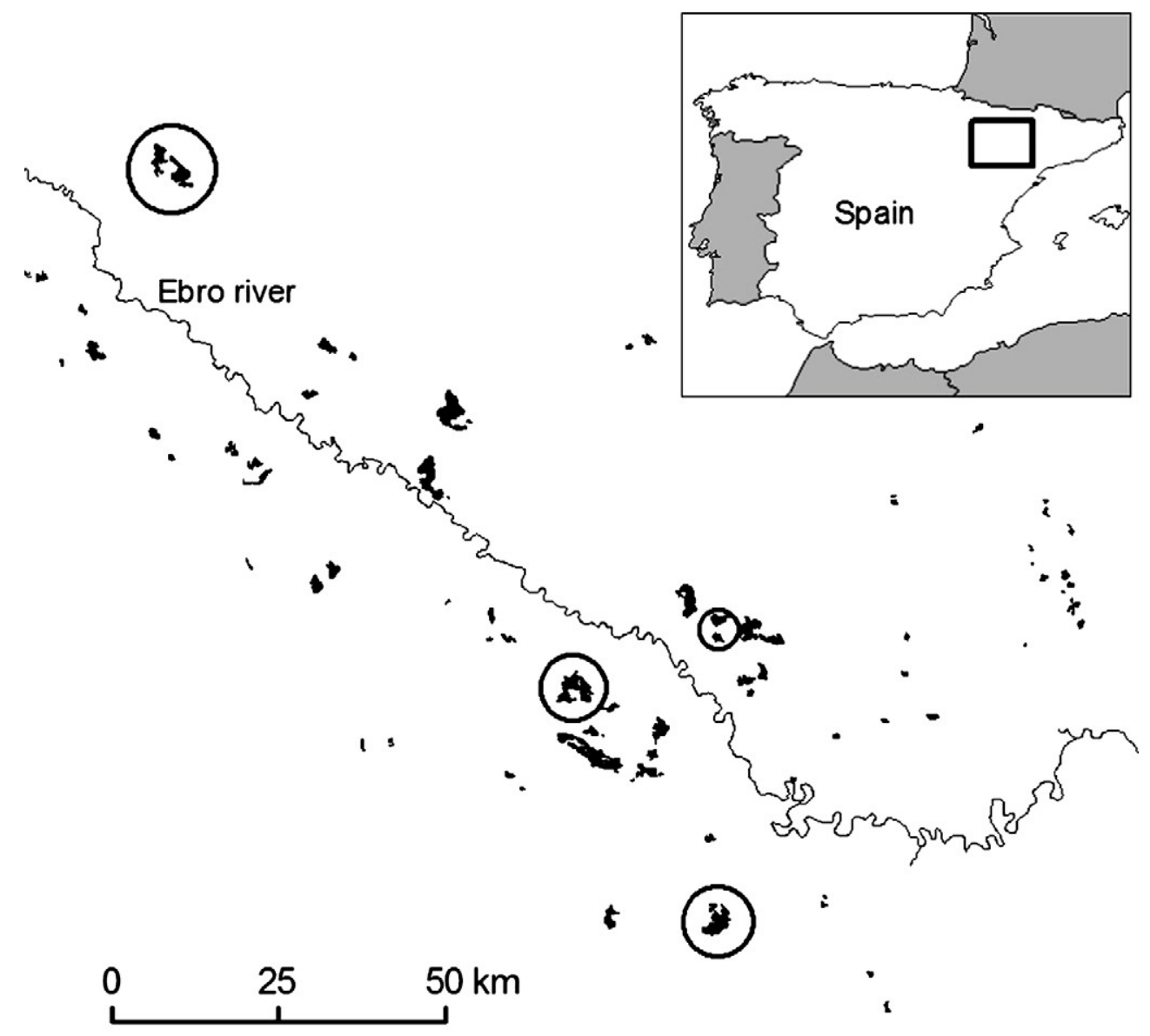

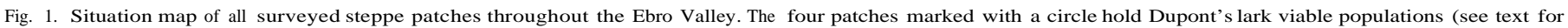
definition).

rian Peninsula (European Environmental Agency 2007; Year 2000 map resolution $=100 \mathrm{~m}$ ) to calculate the percentage of land-use cover in the matrix surrounding each patch, using the categories listed in Appendix F. The three used land-use categories summed up between $83 \%$ and $97 \%$ of the cover in the landscape matrix. Moreover, we computed the number of Dupont's Lark territories inside this buffer.

\subsection{Statistical analyses}

We analyzed the data within a generalized linear model framework, considering both linear and quadratic terms when they had biological meaning. Occurrence models were built with a binomial distribution of errors and a logistic link function, whereas density models were analyzed with a normal distribution of errors and an identity link function. In a first step, we applied a forward stepwise procedure to exclude variables that did not contribute significantly $(\mathrm{P}>0.05)$ to the explained deviance. Final candidate models included only significant variables, and the $\mathrm{AIC}_{\mathrm{c}}$ (Burnham and Anderson, 2002) was used to select the most parsimonious ones.

\subsubsection{Analyses of habitat characteristics at patch level}

The fine-grained data collected inside the patches permitted us to account for variability between years and transects. Hence, we used generalized linear mixed models (GLMM) applying the GLIMMIX procedure integrated in SAS 9.2 to analyze the occurrence and density of Dupont's lark. Year, patch identity and transect identity nested within patch were entered as random factors.
2.6.2. Analyses of landscape attributes at metapopulation level

To include the spatial effects at the metapopulation level we analyzed Dupont's lark occurrence and density with generalized linear models (GLMs) correcting for spatial autocorrelation by including a spatial term of the form $x+y+x^{2}+x y+y^{2}+x^{3}+-$ $x^{2} y+x y^{2}+y^{3}$ (Legendre and Legendre, 1998). Prior to analysis, the spatial coordinates of the sample locations $x$ and $y$ were centered on their respective means to reduce collinearity with higher order terms (Legendre and Legendre, 1998) and standardized to unit variance.

2.6.2.1. Deviance and hierarchical partitioning procedure. Only occurrence models at the metapopulation level included significant effects of several predictor variables belonging to three different predictor groups (see Section 3). Hence, we chose a partitioning framework to identify their relative importance for explaining the occurrence of Dupont's lark. In a first step, we built separate models for the occurrence of Dupont's lark at the metapopulation level using patch characteristics, connectivity and landscape matrix variables as predictor groups. Then, using a series of (partial) logistic regression GLMs, we performed deviance partitioning to decompose the deviance among these three predictor groups (see Heikkinen et al., 2005 for a detailed description). Our approach led to eight fractions: (a) pure effect of patch characteristics; (b) pure effect of connectivity; (c) pure effect of landscape matrix; and combined deviance due to the joint effects of (d) patch characteristics and connectivity; (e) patch characteristics and landscape matrix; (f) connectivity and landscape matrix; and (g) the three 
groups of predictor variables and eventually the unexplained variance. We obtained the total variation explained from the regression of all significant explanatory variables of the three groups ("'general model"). Again, we accounted for spatial autocorrelation by fitting it as an additional term in this model. Finally, we performed a hierarchical partitioning including only those variables retained as significant in previous models to identify their independent and conjoint contributions (Mac Nally, 2000). We used R Version 2.8.1 and the hier.part package (Walsh and Mac Nally, 2008) for the partitioning analyses.

\subsubsection{Extinction analysis}

Due to data paucity, the GLMs for extinction probability at the metapopulation level had convergence problems when we included the spatial trend surface correction term. Therefore, we built GLMMs for the probability that a steppe patch had gone extinct by using a binomial distribution of errors (0: occupied, 1: extinct) and a logistic link function. According to the spatial pattern of Dupont's lark song, patches separated by more than $5 \mathrm{~km}$ appear to form an independent unit (Laiolo, 2008). Therefore, we assigned all the steppe patches separated by less than $5 \mathrm{~km}$ from the next patch to the same zone (Appendix A), which was entered as random factor to correct for spatial non-independence.

\section{Results}

\subsection{Habitat characteristics at patch level}

In spite of the wide array of predictors measured at the patch level and their high variability throughout our study area (see Appendices B and C), we failed to detect any significant effect for the occurrence, density and extinction models. The patterns of abundance and distribution of the Dupont's lark were neither related to the attributes characterizing vegetation structure and grazing pressure (all P-values $>0.09$ ), nor to arthropod diversity and biomass (all P-values $>0.19$ ). Again, we did not find any significant effect of the density and richness of potentially competing steppe passerines (all P-values $>0.44$ ), or the abundance of predators (all P-values $>0.15$ ) on the occurrence, density and extinction of larks.

\subsection{Landscape attributes at metapopulation level}

\subsubsection{Occurrence}

We built separate models for each predictor group of landscape attributes at the metapopulation level. For the patch characteristics, the model predicted an increasing probability of occurrence with patch size. We detected as well a positive relationship between Dupont's lark occurrence and connectivity characterized by the indices $C_{1}, C_{2}$, and $C_{4}$. Finally, we detected a positive effect of the cover of natural vegetation, as well as a negative effect of the cover of non-irrigated arable land in the landscape matrix.
Adding more than one variable of the respective predictor group did not result in model improvement. The most parsimonious model for each predictor group is shown in Table 1 . The connectivity index $\mathrm{C}_{1}$ was separated by more than 4 DAIC $_{c}$ from the other candidate models. However, models including the percentages of natural vegetation and non-irrigated arable land in the landscape matrix were statistically equivalent, suggesting that both variables were to some extent redundant. The cover of natural vegetation in the landscape matrix is likely to be biologically more relevant for the Dupont's lark, and was therefore selected together with patch size and $C_{1}$ for the general model of the variance partitioning approach (Fig. 3).

3.2.1.1. Variance and hierarchical partitioning. The models including all three predictor groups (patch characteristics, connectivity and landscape matrix) explained together $52 \%$ of the variance in the data set (Fig. 2). The joint effect of the three predictor groups was the most important factor ( $g=25 \%$ of the variance explained). The remaining variance was explained by the pure effects of connectivity $(b=9 \%)$ and landscape matrix $(c=7 \%)$, the joint effect of connectivity and landscape matrix ( $f=6 \%$ ), the pure effect of patch size $(a=6 \%)$, and the joint effect of patch size and connectivity ( $d=2 \%)$, respectively. The spatial term accounted for a variable proportion of variability in the data set, being more important for patch size and landscape matrix (64.4\% and $62.5 \%$, respectively) than for connectivity models (57.0\%). Eventually, the hierarchical partitioning analysis revealed that the distance to the nearest occupied patch had the most important independent contribution to explaining the probability of Dupont's lark occurrence (46.3\%), followed by the cover of natural vegetation in the landscape matrix outside the steppe patch (29.4\%) and the patch size (24.3\%).

\subsubsection{Density}

The only model with a statistically significant effect included patch size (GLM, intercept $\pm \mathrm{SE}=0.109 \pm 0.030$, estimate $\pm \mathrm{SE}=$ $\left.-0.013 \pm 0.006, \mathrm{df}=30, \mathrm{~V}^{2}=4.20, \mathrm{P}<0.05\right)$. Note that observed densities increased with shrinking patch size below a patch size threshold of ca. 200 ha (Fig. 4).

\subsubsection{Extinction}

Two alternative univariable, statistically significant models predicted that extinction probabilities of occupied patches increased with distance to the next occupied patch (GLMM, intercept \pm $\mathrm{SE}=-2.361 \pm 0.717, \quad$ estimate $\pm \mathrm{SE}=0.129 \pm 0.060, \quad \mathrm{~F}_{1,21}=4.56$, $\mathrm{P}<0.05$ ) and the geographical centre of the Ebro Valley metapopulation (GLMM, intercept $\pm \mathrm{SE}=-3.930 \pm 1.248$, estimate $\pm \mathrm{SE}=$ $\left.0.050 \pm 0.020, \mathrm{~F}_{1,21}=6.33, \mathrm{P}<0.05\right)$.

\section{Discussion}

Most current approaches to explain animal distribution patterns in fragmented landscapes have focused on habitat quality,

Table 1

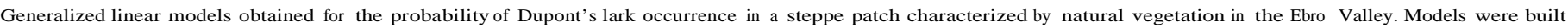

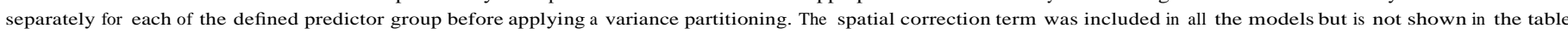
for simplicity. Degrees of freedom: 64 .

\begin{tabular}{|c|c|c|c|c|c|c|c|}
\hline Predictor group & Variables & Estimate & SE & v2 & $\mathrm{P}$ & $\mathrm{AIC}_{\mathrm{c}}$ & $\mathrm{D} \mathrm{AIC}$ \\
\hline 1. Patch characteristics & Patch size & 0.648 & 0.423 & 5.57 & $<0.05$ & & \\
\hline \multirow[t]{3}{*}{ 2. Connectivity } & $\mathrm{C}_{1}$ (Distance to the nearest occupied patch) & -0.299 & 0.103 & 15.09 & $<0.001$ & 75.90 & 0.00 \\
\hline & $C_{2}$ (Distance to the average coordinate of all patches) & -0.394 & 0.153 & 10.60 & $<0.01$ & 80.39 & 4.49 \\
\hline & $\mathrm{C}_{4}$, see text for details & $2.20 \mathrm{E} 7$ & $2.21 \mathrm{E} 6$ & 7.19 & $<0.01$ & 83.80 & 7.90 \\
\hline \multirow[t]{2}{*}{ 3. Landscape matrix } & Non-irrigated arable land (\%) & -0.266 & 0.108 & 9.53 & $<0.01$ & 81.46 & 0.00 \\
\hline & Natural vegetation (\%) & 0.276 & 0.112 & 8.86 & $<0.01$ & 82.14 & 0.68 \\
\hline
\end{tabular}




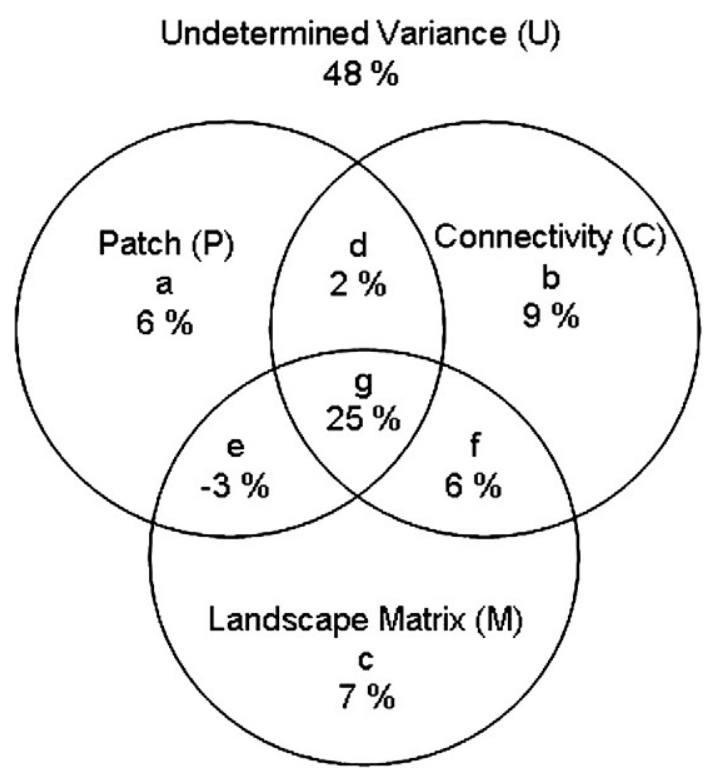

Fig. 2. Results of variance partitioning for the occurrence of Dupont's lark at the metapopulation level in terms of the fractions of variance explained. Variance is explained by three groups of explanatory variables: P (patch characteristics), C (connectivity) and (M) landscape matrix, and $U$ is the undetermined variance; a-c are unique effects of patch characteristics, connectivity and landscape matrix, respectively; while $\mathrm{d}-\mathrm{g}$ are fractions indicating their joint effects.

patch area and connectivity. We analyzed here an additional landscape attribute, the composition of the non-occupied landscape matrix, and showed that the independent effect of this landscape attribute can outweigh some of the former ones. This result suggests that the effect of the intervening matrix may have essential importance for the persistence of species in highly fragmented habitat networks. This scenario might become more frequent for a wide array of threatened species or populations, given that loss and fragmentation of habitat continues occurring from local to global scale.

\subsection{Absence of habitat quality effects at the patch level}

One surprising result of this study is that despite testing a wide variety of ecological factors we failed to detect any statistically significant effect of habitat quality on occurrence, density or extinction of Dupont's larks. We think that three main reasons may explain this result. First, all sampled areas were characterized by natural steppe vegetation and flat terrain, consequently fulfilling the fundamental habitat requirements of the Dupont's lark (Cramp, 1988; Seoane et al., 2006). The habitat characteristics, however, differed widely throughout the different sampled patches (Appendices B and C). Contrarily to the Dupont's lark, the occurrence and density of five sympatrically coexisting lark species in our study area were indeed influenced by the vegetation structure, its botanical composition and arthropod availability (Vögeli, Serrano, Tella, unpubl. data). Based on this evidence, we are confident of having measured at least to some extent the habitat characteristics with ecological relevance, but our stratified sampling protocol could have been centered on those patches, currently occupied or not, satisfying the basic habitat requirements of the species. Second, the analyzed Dupont's lark metapopulation is not at equilibrium, as indicated by the overall negative population trend and the frequent episodes of local extinction reported in recent decades (Tella et al., 2005). Together with the results obtained at the metapopulation level, this fact seems to indicate that metapopulation processes are currently of higher importance for explaining distri-
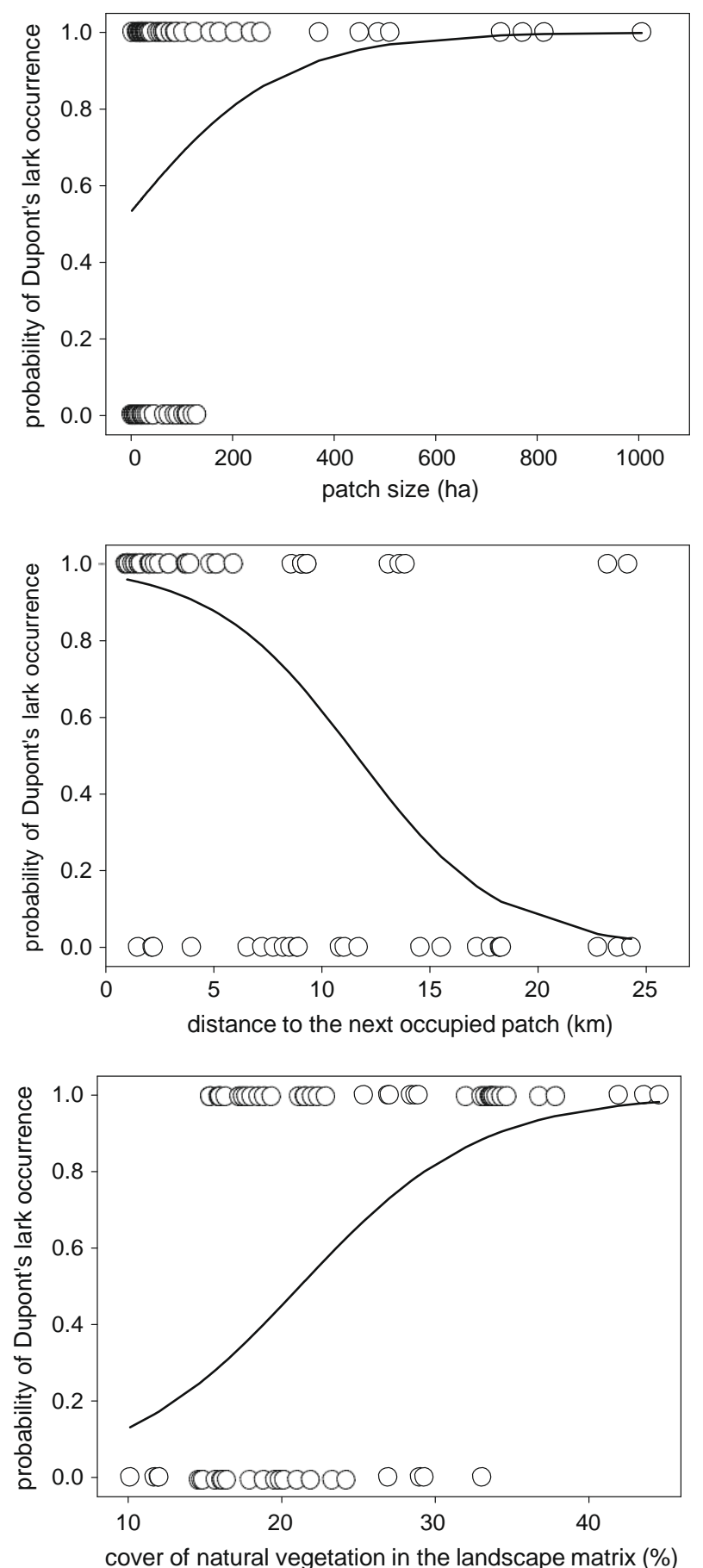

Fig. 3. Univariable relationships between the probability of Dupont's Lark occurrence in a steppe patch and the best predictor variables for patch characteristics, connectivity, and landscape matrix, respectively. These predictors were used for the partitioning approach (see Appendix F).

bution patterns. For example, suitable patches with an unfavorable localization in terms of isolation and intervening matrix could be hardly rescued from stochastic extinction by means of immigration, even if they are characterized by high intrinsic habitat quality. Third, these metapopulation effects could be exacerbated by conspecific attraction (Laiolo and Tella, 2008). Conspecific attraction may reduce search costs and has often been claimed for when interpreting patterns of aggregation in avian species (Serrano and Tella, 2003), potentially accentuating the decline of small and isolated populations (Fletcher, 2006). 


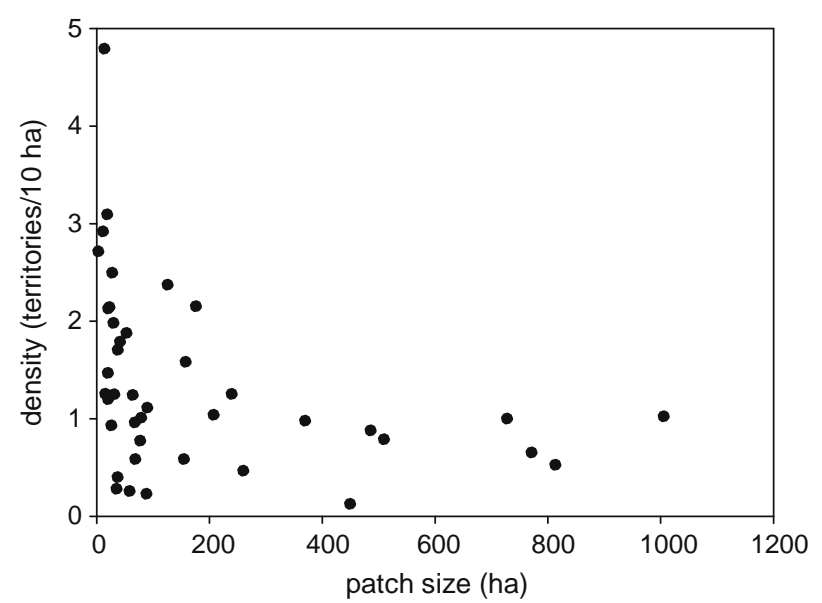

Fig. 4. Relationship between Dupont's lark density and patch size. Note that density values stabilize for patch sizes above 200 ha.

\subsection{Determinants of Dupont's lark distribution at the metapopulation level}

Landscape attributes at the metapopulation level determined the persistence and the spatial distribution of the Dupont's lark. Their significant contribution to explain occurrence, density and extinction reinforced the argument that they might indeed override the local effects of habitat quality within the patches. Whereas Dupont's lark occurrence was influenced by variables from all three predictor groups at the metapopulation level, density and extinction events were exclusively related to connectivity.

\subsubsection{Occurrence}

More than half (31\% of 52\%) of the total explained variance of the species' occurrence in the first step of variance partitioning was related to the joint effect of connectivity and landscape matrix, and the joint effect between the three predictor groups. Hence, Dupont's lark occurrence seems principally determined by the interactions among patch size, connectivity and landscape matrix and not exclusively by one predictor or predictor group. The Dupont's lark distribution analyzed here likely depicts a static snapshot of a dynamic metapopulation where dispersal probably plays a critical role (Hanski, 2001). The effect of habitat fragmentation can be especially important for species with poor dispersal abilities, strongly determining occurrence patterns in highly fragmented habitat networks with large proportions of hostile intervening landscape matrix (Castellón and Sieving, 2006). In this sense, the dispersal attitude of Dupont's lark in the Ebro Valley seems to be limited. Physical and acoustic capture-mark-recapture studies hardly detected movements of Dupont's larks between occupied habitat patches, although more than half of them are separated by only 1-3 km (Appendix A). None of the 312 color-banded individuals in our study area was re-sighted outside the patch where it was marked (Vögeli et al., 2008), although nine of 333 males (2.7\%) in seven patches were classified as immigrants by acoustic marking (Laiolo and Tella, 2008, Laiolo, unpubl. data).

Both variance and hierarchical partitioning identified connectivity and landscape matrix as the most important determinants for Dupont's lark occurrence. The distance to the next occupied patch had the strongest effect among the measured connectivity indices, although those weighting the distances among all patches in a metapopulation have been found to be superior to simple connectivity measures elsewhere (e.g. Moilanen and Nieminen, 2002). The fact that the connectivity effects prevailed at a reduced spatial scale highlighted the species' remarkably disturbed metapopula- tion dynamics in our study area. The landscape matrix had the second strongest independent effect on Dupont's lark occurrence, suggesting that the species has a pronounced sensitivity to the land cover types surrounding the habitat patches, which apparently differ in their resistance to the movement of individuals among them. Increasing theoretical and empirical evidence shows that metapopulation dynamics are widely influenced by the matrix heterogeneity (Vandermeer and Carvajal, 2001). Concretely, our results indicate that the existence of patches of natural vegetation in the matrix, even when not appropriated for sustaining breeding populations of the species, could act as stepping-stones, which may facilitate dispersal and buffer local populations against extinction.

The second step of our variance partitioning approach identified an important contribution of the spatial correction term to the total variance explained. The occupied habitat patches seemed indeed aggregated rather than randomly distributed, making evident the fundamental importance of the landscape context for this metapopulation.

\subsubsection{Density and extinction events}

Whereas the Dupont's lark densities were fairly constant in habitat patches larger than 200 ha, its values increased exponentially towards smaller patch sizes (Fig. 4). Laiolo and Tella (2006) found a similar pattern in Dupont's lark populations throughout Spain, which has been predicted for species in fragmented landscapes whose probability to cross the boundary from habitat to matrix is low (Tischendorf et al., 2005). The limited connectivity of many small patches hampering Dupont's lark dispersal may therefore lead to a crowding effect in these patches (Debinski and Holt, 2000). Hence, Dupont's lark density values likely constitute a misleading surrogate of habitat quality, as found in other bird species inhabiting human-disturbed landscapes (Bock and Jones, 2004).

Theoretical models predict a higher probability of extinction for populations at a species range edge among other reasons as a consequence to their reduced neighborhood and lower connectivity with the rest of the metapopulation (Holt et al., 2005). Indeed, the three most recently extinct patches (see Appendix A), with no evident habitat loss or degradation, are located in the periphery of the Ebro Valley metapopulation. The negative influence of geographic isolation was underlined by the fact that steppe patches were more likely to go extinct with increasing distance to the next occupied patch.

\subsection{Conservation implications}

Variance and hierarchical partitioning has successfully been employed in population ecology (Heikkinen et al., 2005). The identification and prioritization of the effects partialled out provide a deeper insight into the relationship between the Dupont's lark and its environment, and might ensure effective conservation measures, which could be calibrated for an optimal trade-off between its costs and benefits. In fact, a conservation management of the Dupont's lark is urgently needed acknowledging its ongoing local and global negative population trends (Tella et al., 2005; BirdLife International, 2008) and the lack of evidence for recolonisations of many small isolated patches were the species has gone extinct. The importance of the joint effects of patch size, connectivity and landscape matrix, and the spatial component suggest that conservation measures should simultaneously involve all three predictor groups and apply to the whole metapopulation rather than to particular patches.

We propose four main guidelines for Dupont's lark conservation. First and most evident, existing occupied patches should be protected and wherever possible amplified until a patch size of 
Table A1

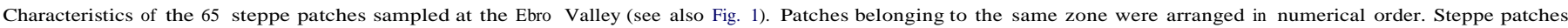

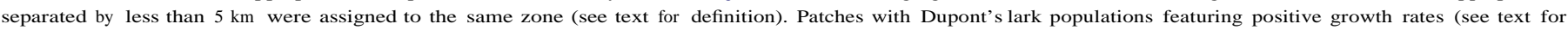
definition) are marked in italic.

\begin{tabular}{|c|c|c|c|c|c|c|c|}
\hline Patch & Zone & Patch size (ha) & $\begin{array}{l}\text { Number } \\
\text { of territories }\end{array}$ & $\begin{array}{l}\text { Density } \\
\text { (territories/10 ha) }\end{array}$ & $\begin{array}{l}\text { Distance to the nearest } \\
\text { occupied patch }(\mathrm{km})\end{array}$ & $\begin{array}{l}\text { Transects realized } \\
\text { (with Dupont's } \\
\text { lark presence) }\end{array}$ & Extinction \\
\hline Albalatillo & Albalatillo & 36.0 & 1 & 0.28 & 24.15 & $2(1)$ & - \\
\hline Alcolea de Cinca & Alcolea de Cinca & 23.2 & 0 & - & 8.89 & $1(0)$ & $\mathrm{Yes}^{\mathrm{a}}$ \\
\hline Ballobar 1 & Ballobar & 94.8 & 0 & - & 8.89 & $3(0)$ & $\mathrm{Yes}^{\mathrm{a}}$ \\
\hline Ballobar 2 & Ballobar & 23.4 & 5 & 2.14 & 4.93 & $1(1)$ & - \\
\hline Ballobar 3 & Ballobar & 30.4 & 6 & 1.98 & 1.41 & - & - \\
\hline Ballobar 4 & Ballobar & 20.9 & 2 & 1.19 & 1.41 & - & - \\
\hline Candasnos & Candasnos & 4.6 & 0 & - & 8.53 & $1(0)$ & No \\
\hline Castelflorite & Castelflorite & 46.4 & 0 & - & 23.69 & - & No \\
\hline Chalamera & Chalamera & 12.6 & 0 & - & 7.23 & - & $\mathrm{Yes}^{\mathrm{a}}$ \\
\hline Ontiñena & Ballobar & 10.1 & 0 & - & 3.97 & $1(0)$ & $\mathrm{Yes}^{\mathrm{a}}$ \\
\hline Ontiñena & Ballobar & 1.6 & 0 & - & 2.16 & - & Yes $^{a}$ \\
\hline Tardienta 1 & Tardienta & 53.4 & 10 & 1.87 & 2.11 & - & - \\
\hline Tardienta 2 & Tardienta & 28.1 & 7 & 2.49 & 2.11 & - & - \\
\hline Valfarta & Valfarta & 27.6 & 0 & - & 18.26 & $1(0)$ & No \\
\hline Alfés & Alfés & 80.0 & 0 & - & 40.87 & - & Yes $^{\mathrm{b}}$ \\
\hline Ablitas 1 & Ablitas 1 & 59.0 & 1 & 0.25 & 3.98 & - & - \\
\hline Ablitas 2 & Ablitas 2 & 111.9 & 0 & - & 6.55 & - & $\mathrm{Yes}^{\mathrm{a}}$ \\
\hline Ablitas 3 & Ablitas 1 & 177.0 & 38 & 2.15 & 3.84 & - & - \\
\hline Bardenas Reales & Bardenas Reales & 814.1 & 42 & 0.52 & 23.22 & - & - \\
\hline Albalate & Albalate & 370.2 & 36 & 0.97 & 9.32 & $11(6)$ & - \\
\hline Alcañíz 1 & Alcañíz 1 & 20.8 & 0 & - & 11.69 & $2(0)$ & Yes $^{\mathrm{b}}$ \\
\hline Alcañíz 2 & Alcañíz 2 & 46.6 & 0 & - & 17.17 & $2(0)$ & Yes $^{\mathrm{b}}$ \\
\hline Azaila & Azaila & 42.1 & 7 & 1.78 & 9.32 & $3(2)$ & - \\
\hline Calanda & Calanda & 5.7 & 0 & - & 22.76 & $1(0)$ & $\mathrm{Yes}^{\mathrm{a}}$ \\
\hline Samper & Samper & 14.6 & 7 & 4.79 & 13.85 & $1(1)$ & - \\
\hline Belchite 1 & Belchite & 771.6 & 50 & 0.65 & 1.01 & $5(5)$ & - \\
\hline Belchite 2 & Belchite & 90.2 & 10 & 1.11 & 1.01 & - & - \\
\hline Belchite 3 & Belchite & 240.0 & 30 & 1.25 & 1.29 & $5(5)$ & - \\
\hline Borja & Borja & 88.8 & 2 & 0.23 & 3.00 & - & - \\
\hline Bujaraloz 1 & Bujaraloz 1 & 75.8 & 0 & - & 24.32 & $2(0)$ & No \\
\hline Bujaraloz 2 & Bujaraloz 2 & 36.8 & 0 & - & 18.31 & $1(0)$ & $\mathrm{Yes}^{\mathrm{a}}$ \\
\hline Cinco Olivas & Cinco Olivas & 19.4 & 6 & 3.09 & 13.58 & $2(2)$ & - \\
\hline Fuentes & Belchite & 260.8 & 12 & 0.46 & 1.01 & $3(2)$ & - \\
\hline Lécera & Lécera & 126.7 & 30 & 2.37 & 13.09 & $4(3)$ & - \\
\hline Longares & Longares & 32.1 & 4 & 1.24 & 3.79 & - & - \\
\hline Magallón & Magallón & 88.5 & 0 & - & 7.77 & - & No \\
\hline Mediana 1 & Belchite & 79.7 & 8 & 1.00 & 1.01 & - & - \\
\hline Mediana 2 & Belchite & 510.1 & 40 & 0.78 & 1.68 & 7 (5) & - \\
\hline Mediana 3 & Belchite & 68.1 & 6 & 0.95 & 1.68 & - & - \\
\hline Mezalocha & Longares & 20.5 & 3 & 1.46 & 3.79 & - & - \\
\hline La Muela & Urrea de Jalón & 105.9 & 0 & - & 1.49 & - & No \\
\hline Pedrola 1 & Pedrola & 124.6 & 0 & - & 11.04 & - & No \\
\hline Pedrola 2 & Pedrola & 133.7 & 0 & - & 10.82 & - & No \\
\hline Pina 1 & Pina & 233.4 & 15 & 0.64 & 2.20 & $3(3)$ & - \\
\hline Pina 2 & Pina & 486.4 & 42 & 0.87 & 2.09 & $8(5)$ & - \\
\hline Pina 3 & Pina & 27.0 & 2 & 0.93 & 1.11 & $2(1)$ & - \\
\hline Pina 4 & Pina & 208.0 & 22 & 0.77 & 1.11 & $3(3)$ & - \\
\hline Pozuelo & Borja & 37.9 & 4 & 0.40 & 3.00 & - & - \\
\hline La Puebla 1 & La Puebla 1 & 38.2 & 6 & 1.70 & 8.60 & $2(2)$ & - \\
\hline La Puebla 2 & La Puebla 2 & 9.2 & 0 & - & 8.90 & $1(0)$ & No \\
\hline Rueda de Jalón & Rueda de Jalón & 21.2 & 3 & 2.12 & 9.08 & - & - \\
\hline Sástago 1 & Sástago 1 & 32.5 & 0 & - & 8.24 & - & $\mathrm{Yes}^{\mathrm{a}}$ \\
\hline Sástago 2 & Sástago 2 & 15.9 & 0 & - & 15.53 & $1(0)$ & No \\
\hline Tarazona & Ablitas 1 & 12.0 & 3 & 2.91 & 3.84 & - & - \\
\hline Tauste 1 & Tauste & 24.2 & 0 & - & 14.54 & - & No \\
\hline Tauste 2 & Tauste & 67.2 & 0 & - & 18.26 & - & No \\
\hline Tauste 3 & Tauste & 114.3 & 0 & - & 17.80 & - & No \\
\hline Urrea de Jalón & Urrea de Jalón & 158.7 & 25 & 1.58 & 9.08 & $3(3)$ & - \\
\hline Villafranca & Pina & 450.0 & 6 & 0.12 & 2.54 & - & - \\
\hline Zaragoza 1 & Zaragoza 1 & 69.0 & 4 & 0.58 & 1.58 & - & - \\
\hline Zaragoza 2 & Zaragoza 2 & 3.7 & 1 & 2.71 & 6.01 & - & - \\
\hline Zaragoza 3 & Zaragoza 1 & 16.0 & 2 & 1.25 & 1.58 & - & - \\
\hline Zaragoza 4 & Zaragoza 3 & 1006.3 & 102 & 1.02 & 5.22 & - & - \\
\hline Zaragoza 5 & Zaragoza 4 & 728.4 & 72 & 1.00 & 5.22 & - & - \\
\hline Zaragoza 6 & Zaragoza 1 & 64.7 & 8 & 1.24 & 2.33 & $4(2)$ & - \\
\hline
\end{tabular}

${ }^{\text {a }}$ Patch extinct before 2004

b Patch extinct between 2004 and 2007.

at least 200 ha. The effects derived from being forced to squeeze into the remaining available habitat patches are likely to be deleterious. Indeed, small patches suffer from a low productivity affect- ing negatively the population growth rates (Laiolo et al., 2008). Second, land-use changes affecting the low intensively agricultural land with significant areas of natural vegetation should be avoided 
in the landscape matrix. Third, areas of natural vegetation should be created in the landscape matrix to increase connectivity and the overall amount of suitable habitat. Finally, improving the connectivity of all habitat patches with the largest viable populations should be prioritized due to their benefit for the whole metapopulation. Creating reserves of natural steppe vegetation through land abandonment represents nowadays the only way to achieve a better connectivity. Although abandoning fields may not always have a positive impact on steppe species adapted to live in traditional agro-ecosystems (e.g. Tella et al., 1998), it may be the only option to reverse negative population trends of steppe specialists such as the Dupont's lark (Laiolo and Tella, 2006).

\section{Acknowledgments}

We are indebted to the numerous helping people during fieldwork, especially P. Laiolo, M.A. Carrero, M. Méndez, and I. Afán. J. Blasco-Zumeta gave essential advice for the arthropod sampling

Table A2

Predictor variables used from transect data to characterize the habitat of Dupont's larks at the patch level. The descriptive values are given at transect level.

\begin{tabular}{|c|c|c|}
\hline Variable & Description & Mean \pm SD (range) \\
\hline \multicolumn{3}{|c|}{ (a) Vegetation and grazing pressure } \\
\hline BSTO & Cover of bare stone (\% cover) & $4.6 \pm 5.5(0-31)$ \\
\hline HERB & Cover of herbaceous plants (\% cover) & $7.2 \pm 10.5(0-74)$ \\
\hline SHRU & Cover of shrubs (\% cover) & $32.5 \pm 9.7(4-73)$ \\
\hline LICH & Cover of lichens (\% cover) & $8.9 \pm 9.3(0-40)$ \\
\hline MOSS & Cover of moss (\% cover) & $1.9 \pm 1.6(0-10)$ \\
\hline BGRO & Cover of bare ground (\% cover) & $45.0 \pm 16.0(7-83)$ \\
\hline HSHR & Height of shrubs $(\mathrm{cm})$ & $3.2 \pm 3.2(0-34)$ \\
\hline HHER & Height of herbaceous plants (cm) & $13.7 \pm 6.3(4-36)$ \\
\hline HOVE & Overall vegetation height $(\mathrm{cm})$ & $13.2 \pm 5.4(4-34)$ \\
\hline NSHE & Sheep feces (number) & $36.2 \pm 82.4(0-674)$ \\
\hline PSHE & Sheep feces (presence/absence) & \\
\hline CVEG & Vegetation community (11 categories) & \\
\hline CVES & $\begin{array}{l}\text { Simplified vegetation community (6 } \\
\text { categories) }\end{array}$ & \\
\hline \multicolumn{3}{|c|}{ (b) Arthropod availability } \\
\hline ARAB & Arthropod abundance (count) & $\begin{array}{l}194.2 \pm 132.0(38- \\
650)\end{array}$ \\
\hline ARMO & Arthropod morphospecies (count) & $30.8 \pm 11.4(13-65)$ \\
\hline ARDI & Arthropod diversity (Shannon index) & $2.4 \pm 0.5(1.2-3.5)$ \\
\hline ARBM & Arthropod biomass (biomass index) & $\begin{array}{l}998.8 \pm 705.0(236 \\
4701)\end{array}$ \\
\hline \multicolumn{3}{|c|}{$\begin{array}{l}\text { (c) Bird densities } \\
\text { and species richness }\end{array}$} \\
\hline BIDI & $\begin{array}{l}\text { Steppe passerine diversity (Shannon } \\
\text { index) }\end{array}$ & $1.4 \pm 0.4(0.5-2.5)$ \\
\hline BIDE & Steppe passerine density (individuals/ha) & $5.5 \pm 2.3(1.2-13.7)$ \\
\hline \multicolumn{3}{|c|}{ (d) Predator abundance } \\
\hline CACO & $\begin{array}{l}\text { Relative abundance of canids and corvids } \\
\text { (individuals/hour) }\end{array}$ & $0.3 \pm 0.5(0.0-1.1)$ \\
\hline PHAP & $\begin{array}{l}\text { Relative abundance of passerine hunting } \\
\text { aerial predators (individuals/hour) }\end{array}$ & $0.2 \pm 0.1 \quad(0.0-0.9)$ \\
\hline
\end{tabular}

and shared together with A. Bueno invaluable information about Dupont's lark localities. The regional governments of Aragón and Navarra kindly provided the GIS data and authorized its use for this study. We thank the LAST-EBD, especially D. Aragonés, for the support with the GIS data. M. Carrete improved greatly the statistical analyses. M.V. was supported by an I3P pre-doctoral fellowship from the Spanish Research Council(CSIC), D.S. by an I3P post-doc-

Table A4

Steppe passerines potentially competing in the breeding season with the Dupont's lark for habitat and food (Cramp, 1988)

\begin{tabular}{l}
\hline Steppe passerine species \\
\hline 1. Greater short-toed lark (Calandrella brachydactyla) \\
2. Thekla lark (Galerida theklae) \\
3. Crested lark (Galerida cristata) \\
4. Calandra lark (Melanocorypha calandra) \\
5. Eurasian skylark (Alauda arvensis) \\
6. Black-eared wheatear (Oenanthe hispanica) \\
7. Spectacled warbler (Sylvia conspicillata) \\
8. Tawny pipit (Anthus campestris) \\
\hline
\end{tabular}

Table A5

Mammal and avian predators considered for calculating the relative abundance index for each predator group.

\begin{tabular}{|c|c|}
\hline Predator category & Species \\
\hline (i) Nest predator & Feral dog (Canis lupus familiaris) \\
\hline (i) Nest predator & Red fox (Vulpes vulpes) \\
\hline (i) Nest predator & Common raven (Corvus corax) \\
\hline (i) Nest predator & Carrion crow (Corvus corone corone) \\
\hline (i) Nest predator & Jackdaw (Corvus monedula) \\
\hline (i) Nest predator & Magpie (Pica pica) \\
\hline $\begin{array}{l}\text { (ii) Passerine hunting aerial } \\
\text { predator }\end{array}$ & $\begin{array}{l}\text { European marsh harrier (Circus } \\
\text { aeruginosus) }\end{array}$ \\
\hline $\begin{array}{l}\text { (ii) Passerine hunting aerial } \\
\text { predator }\end{array}$ & Hen harrier (Circus cyaneus) \\
\hline $\begin{array}{l}\text { (ii) Passerine hunting aerial } \\
\text { predator }\end{array}$ & Montagu's harrier (Circus pygargus) \\
\hline $\begin{array}{l}\text { (ii) Passerine hunting aerial } \\
\text { predator }\end{array}$ & Sparrowhawk (Accipiter nisus) \\
\hline $\begin{array}{l}\text { (ii) Passerine hunting aerial } \\
\text { predator }\end{array}$ & Merlin (Falco columbarius) \\
\hline $\begin{array}{l}\text { (ii) Passerine hunting aerial } \\
\text { predator }\end{array}$ & Lesser kestrel (Falco naumanni) \\
\hline $\begin{array}{l}\text { (ii) Passerine hunting aerial } \\
\text { predator }\end{array}$ & Common kestrel (Falcotinnunculus) \\
\hline $\begin{array}{l}\text { (ii) Passerine hunting aerial } \\
\text { predator }\end{array}$ & Eurasian hobby (Falco subbuteo) \\
\hline $\begin{array}{l}\text { (ii) Passerine hunting aerial } \\
\text { predator }\end{array}$ & Peregrine falcon (Falco peregrinus) \\
\hline $\begin{array}{l}\text { (ii) Passerine hunting aerial } \\
\text { predator }\end{array}$ & Booted eagle (Hieraatus pennatus) \\
\hline $\begin{array}{l}\text { (ii) Passerine hunting aerial } \\
\text { predator }\end{array}$ & $\begin{array}{l}\text { Southern grey shrike (Lanius } \\
\text { meridionalis) }\end{array}$ \\
\hline
\end{tabular}

Table A3

Classification of vegetation communities in the Ebro Valley (after Braun-Blanquet and de Bolós, 1957).

\begin{tabular}{|c|c|c|c|c|c|}
\hline CVEG & CVES & Class & Order & Association & Type \\
\hline 1 & 1 & Thero-Brachypodieta & Rosmarinetalia & Rosmarineto-Linetum suffruticosi & Low disturbance: no dominant species, high diversity \\
\hline 2 & 2 & Thero-Brachypodieta & Lygeo-Stipetalia & Lygeeto-Stipetum lagascae & Low disturbance: low diversity due to shallow profile depth \\
\hline 3 & 1 & Thero-Brachypodieta & Lygeo-Stipetalia & Lygeeto-Stipetum lagascae & Low disturbance: no dominant species, high diversity \\
\hline 4 & 2 & Thero-Brachypodieta & Lygeo-Stipetalia & Lygeeto-Stipetum lagascae & Medium disturbance: appearance of Artemisia herba-alba \\
\hline 5 & 3 & Thero-Brachypodieta & Lygeo-Stipetalia & Lygeeto-Stipetum lagascae & High disturbance: dominance of Artemisia herba-alba \\
\hline 6 & 4 & Ononido-Rosmarianetea & Gypsophilion & Helianthemetum squamati & Low disturbance: dominance of Helianthemum squamatum \\
\hline 7 & 4 & Ononido-Rosmarianetea & Gypsophilion & Helianthemetum squamati & Low disturbance: no dominant species \\
\hline 8 & 5 & Ononido-Rosmarianetea & Gypsophilion & Helianthemetum squamati & Medium disturbance: appearance of Artemisia herba-alba \\
\hline 9 & 5 & Ononido-Rosmarianetea & Gypsophilion & Helianthemetum squamati & High disturbance: dominance of Artemisia herba-alba \\
\hline 10 & 4 & Ononido-Rosmarianetea & Gypsophilion & Helianthemetum squamati & Low disturbance: dominance of Rosmarinus officinalis \\
\hline 11 & 6 & Salicornietea & Limonietalia & Suadetum brevifoliae & \\
\hline
\end{tabular}


Table A6

Predictor variables used to characterize the landscape attributes at metapopulation level. Increasing values of $\mathrm{C}_{3}$ and $\mathrm{C}_{4}$ correspond to less isolated or better connected study sites, respectively.

\begin{tabular}{|c|c|c|}
\hline \multicolumn{2}{|c|}{ Variable } & Description \\
\hline \multicolumn{3}{|c|}{ (a) Patch characteristics } \\
\hline \multicolumn{2}{|l|}{ PASI } & Patch size (area) \\
\hline \multicolumn{3}{|c|}{ (b) Connectivity } \\
\hline $\mathrm{C}_{1}$ & & Distance to the nearest occupied patch $(\mathrm{km})$ \\
\hline $\mathrm{C}_{2}$ & & Distance to the average coordinate of all patches $(\mathrm{km})$ \\
\hline $\mathrm{C}_{3}$ & & Connectivity index $C_{3}=R \exp \left(-d_{i j}\right) N_{j}$, see text for details \\
\hline $\mathrm{C}_{4}$ & & Connectivity index $\mathrm{C}_{4}=\mathrm{R} \exp \left(-\mathrm{d}_{\mathrm{ik}}\right)$, see text for details \\
\hline \multicolumn{3}{|c|}{ (c) Landscape matrix } \\
\hline & & CORINE categories \\
\hline NIAL & $\begin{array}{l}\text { Non-irrigated } \\
\text { arable land (\%) }\end{array}$ & $\begin{array}{l}\text { Non-irrigated arable land, mainly cereal } \\
\text { cultivations }\end{array}$ \\
\hline \multirow[t]{6}{*}{ INTA } & $\begin{array}{l}\text { Intensive } \\
\text { agriculture (\%) }\end{array}$ & Permanently irrigated land \\
\hline & & Rice fields \\
\hline & & Vineyards \\
\hline & & Fruit trees and berry plantations \\
\hline & & Olive groves \\
\hline & & Complex cultivation patterns \\
\hline \multirow[t]{5}{*}{ NVEG } & $\begin{array}{l}\text { Natural } \\
\text { vegetation (\%) }\end{array}$ & $\begin{array}{l}\text { Agricultural land, mainly characterised by } \\
\text { significant areas of natural vegetation (where }\end{array}$ \\
\hline & & Dupont's larks were not detected) \\
\hline & & Natural grasslands \\
\hline & & Sclerophyllous vegetation \\
\hline & & Transitional woodland-shrub \\
\hline
\end{tabular}

toral contract from the CSIC, such as M.V., D.S., and J.L.T. by an Excellence Project of the Junta of Andalucía to J.L.T.

\section{Appendix A}

See Table A1.

\section{Appendix B}

See Table A2.

\section{Appendix C}

See Table A3.

\section{Appendix D}

See Table A4.

\section{Appendix E}

See Table A5.

\section{Appendix F}

See Table A6.

\section{References}

Aragüés, A., 1992. Estudio de la alondra de Dupont (Chersophilus duponti) en la región aragonesa. $\mathrm{PhD}$ thesis. Universidad de Zaragoza, Spain.

BirdLife International, 2008. Chersophilus duponti. 2008 IUCN Red list of threatened species. <http://www.iucnredlist.org> (accessed May 2009).

Bock, C.E., Jones, Z.F., 2004. Avian habitat evaluation: should counting birds count? Frontiers in Ecology and Environment 2, 403-410.

Borcard, D., Legendre, P., Drapeau, P., 1992. Partialling out the spatial component of ecological variation. Ecology 73, 1045-1055.
Braun-Blanquet, J., de Bolós, O., 1957. Les groupement végétaux du bassin moyen de l'Ebre et leur dynamisme. Anales de la Estación Experimental de Aula Dei 5, 1266.

Burnham, K.P., Anderson, D.R., 2002. Model Selection and Multimodel Inference. A Practical Information-theoretic Approach, second ed. Springer, Heidelberg.

Carrete, M., Serrano, D., López, G., Illera, J.C., Vögeli, M., Delgado, A., Tella, J.L., 2009. Goats, birds, and emergent diseases: apparent and hidden effects of exotic species on an island environment. Ecological Applications 19, 840-853.

Castellón, T.D., Sieving, K.E., 2006. Landscape history, fragmentation, and patch occupancy: models for a forest bird with limited dispersal. Ecological Applications 16, 2223-2234.

Caughley, G., 1994. Directions in conservation biology. Journal of Animal Ecology 63, 215-244.

Cramp, S., 1988. The Birds of the Western Palaearctic, vol. 5. Academic Press, London.

Debinski, D.M., Holt, R.D., 2000. A survey and overview of habitat fragmentation experiments. Conservation Biology 14, 342-355.

Fletcher Jr., R.J., 2006. Emergent properties of conspecific attraction in fragmented landscapes. The American Naturalist 168, 207-219.

Garza, V., Suárez, F., Tella, J.L., 2004. Alondra de Dupont, Chersophilus duponti. In: Madroño, A., González, C., Atienza, J.C. (Eds.), Libro Rojo de las Aves de España. Dirección General para la Biodiversidad-SEO/Birdlife, Madrid, pp. 309-312.

Garza, V., Suárez, F., Herranz, J., Traba, J., De La Morena, E.G., Morales, M.B., González, R., Castañeda, M., 2005. Space use and habitat selection of the endangered Dupont's lark in Spain: the breeding and postbreeding periods. Ardeola 52, 133-146.

Hanski, I., 2001. Population dynamic consequences of dispersal in local populations and in metapopulations. In: Clobert, J., Danchin, E., Dhondt, A.A., Nichols, J.D. (Eds.), Dispersal. Oxford University Press, Oxford, pp. 283-298.

Hanski, I., Gilpin, M.E., 1997. Metapopulation Biology: Ecology, Genetics, and Evolution. Academic Press, San Diego.

Hanski, I., Kuussaari, M., Nieminen, M., 1994. Metapopulation structure and migration in the butterfly Melitaea cinxia. Ecology 75, 747-762.

Heikkinen, R.K., Luoto, M., Kuussaari, M., Pöyry, J., 2005. New insights into butterfly-environment relationships using partitioning methods. Proceedings of the Royal Society of London B 272, 2203-2210.

Holt, R.D., Keitt, T.H., Lewis, M.A., Maurer, B.A., Taper, M.L., 2005. Theoretical models of species' borders: single species approaches. Oikos 108, 18-27.

Jaquiéry, J., Guélat, J., Broquet, T., Berset-Brändli, L., Pellegrini, E., Moresi, R., Hirzel, A.H., Perrin, N., 2008. Habitat-quality effects on metapopulation dynamics in greater white-toothed shrews, Crocidura russula. Ecology 89, 2777-2785.

Laiolo, P., 2008. Characterizing the spatial structure of songbird cultures. Ecological Applications 18, 1774-1780.

Laiolo, P., Tella, J.L., 2006. The fate of unproductive and unaesthetic habitats: recent changes in Iberian steppes and their endangered avifauna. Environmental Conservation 33, 223-232.

Laiolo, P., Tella, J.L., 2008. Social determinants of songbird vocal activity and implications for the persistence of small populations. Animal Conservation 11, $433-441$.

Laiolo, P., Vögeli, M., Serrano, D., Tella, J.L., 2007. Testing acoustic versus physical marking: two complementary methods for individual-based monitoring of elusive species. Journal of Avian Biology 38, 672-681.

Laiolo, P., Vögeli, M., Serrano, D., Tella, J.L., 2008. Song diversity predicts the viability of fragmented bird populations. PLoS ONE 3, e1822.

Legendre, P., Legendre, L., 1998. Numerical Ecology, second ed. Elsevier Science, Amsterdam

Mac Nally, R., 2000. Regression and model building in conservation biology, biogeography and ecology: the distinction between - and reconciliation of "predictive” and "explanatory” models. Biodiversity and Conservation 9, 655671.

Moilanen, A., Nieminen, M., 2002. Simple connectivity measures in spatial ecology. Ecology 83, 1131-1145.

Oliver, I., Beattie, A.J., 1993. A possible method for the rapid assessment of biodiversity. Conservation Biology 7, 572-578.

Prugh, L.R., Hodges, K.E., Sinclair, A.R.E., Brashares, J.S., 2008. Effect of habitat area and isolation on fragmented animal populations. Proceedings of the National Academy of Sciences of the United States of America 105, 20770-20775.

Rabasa, S.G., Gutiérrez, D., Escudero, A., 2008. Relative importance of host plant patch geometry and habitat quality on the patterns of occupancy, extinction, and density of the monophagous butterfly Iolana iolas. Oecologia 156, 491-503.

Ricketts, T.H., 2001. The matrix matters: effective isolation in fragmented landscapes. The American Naturalist 158, 87-99.

Seoane, J., Justribó, J.H., García, F., Retamar, J., Rabadán, C., Atienza, J.C., 2006. Habitat-suitability modelling to assess the effects of land-use changes on Dupont's lark Chersophilus duponti: a case study in the Layna Important Bird Area. Biological Conservation 128, 241-252.

Serrano, D., Tella, J.L., 2003. Dispersal within a spatially structured population of lesser kestrels: the role of spatial isolation and conspecific attraction. Journal of Animal Ecology 72, 400-410.

Shannon, C.E., Weaver, W., 1949. A Mathematical Model of Communication. University of Illinois Press, Urbana.

SIGPAC, 2008. Sistema de información geográfica de parcelas agrícolas (SIGPAC). $<$ http://www.mapa.es/es/sig/pags/sigpac/intro.htm> (accessed February 2009).

Tella, J.L., Forero, M.G., Hiraldo, F., Donázar, J.A., 1998. Conflicts between Lesser kestrel conservation and European agricultural policies as identified by habitat use analyses. Conservation Biology 12, 593-604. 
Tella, J.L., Vögeli, M., Serrano, D., Carrete, M., 2005. Current status of the threatened Dupont's lark in Spain: overestimation, decline, and extinction of local populations. Oryx 39, 90-94.

Tellería, J.L., Ramírez, A., Galarza, A., Carbonell, R., Pérez-Tris, J., Santos, T., 2008. Geographical, landscape and habitat effects on birds in Northern Spanish farmlands: implications for conservation. Ardeola 55, 203-219.

Thomas, J.A., Bourn, N.A.D., Clarke, R.T., Stewart, K.E., Simcox, D.J., Perman, G.S., Curtis, R., Goodger, B., 2001. The quality and isolation of habitat patches both determine where butterflies persist in fragmented landscapes. Proceedings of the Royal Society of London B 268, 1791-1796.
Tischendorf, L., Grez, A., Zaviezo, T., Fahrig, L., 2005. Mechanisms affecting population density in fragmented habitat. Ecology and Society 10. <http:// www.ecologyandsociety.org/vol10/iss1/art7> (accessed January 2009).

Vandermeer, J., Carvajal, R., 2001. Metapopulation dynamics and the quality of the matrix. The American Naturalist 158, 211-220.

Vögeli, M., Laiolo, P., Serrano, D., Tella, J.L., 2008. Who are we sampling? Apparent survival differs between methods in a secretive species. Oikos 117, 1816-1823. Walsh, C., Mac Nally, R., 2008. hier.part: Hierarchical partitioning, R package version 1.0.3. 